\title{
Prognostic Value of CD25 Expression on Lymphocytes and Tumor Cells in Squamous-Cell Carcinoma of the Head and Neck
}

\author{
David Loose, ${ }^{1}$ Alberto Signore, ${ }^{2,3}$ Elena Bonanno, ${ }^{4}$ Hubert Vermeersch, ${ }^{1}$ Rudi Dierckx ${ }^{2,5}$ \\ Philippe Deron, ${ }^{1}$ and Christophe Van de Wiele ${ }^{2,5}$ \\ ${ }^{1}$ Department of Head and Neck Surgery, University Hospital Ghent, Ghent, Belgium \\ ${ }^{2}$ Nuclear Medicine Unit, Departments of Clinical Sciences and Radiological Sciences, Second Faculty \\ of Medicine, University "La Sapienza," Rome, Italy \\ ${ }^{3}$ Department of Nuclear Medicine and Molecular Imaging, University Medical Center Groningen, \\ University of Groningen, Groningen, The Netherlands \\ ${ }^{4}$ Department of Biopathology and Diagnostic Imaging, University “Tor Vergata," Rome, Italy \\ ${ }^{5}$ Departments of Nuclear Medicine, Experimental Cancerology and Radiotherapy, University Hospital \\ Ghent, Ghent, Belgium
}

\begin{abstract}
ASTRACT
$\mathrm{CD}^{+} \mathrm{CD} 25^{+} \mathrm{T}$-cells play a central role in initiating and maintaining anticancer immune response. On the other hand, $C D 25^{+}$is also expressed on tumor cells, the meaning of which is currently unclear. Therefore, this study was designed to determine the prognostic value of the presence of $C D 4^{+} C D 25^{+} T$-cells in squamous-cell carcinoma of the head and neck (SCCHN) and of CD25 on SCCHN tumor cells. Thirtyfive (35) patients diagnosed with a primary untreated SCCHN were included in this study. Instantly snapfrozen resection or biopsy specimens were analyzed by immunohistochemistry. Histologic results obtained were related to overall, disease-free survival. On univariate analysis, both lymph-node status and the number of $\mathrm{CD}^{2} 5^{+}$lymphocytes were associated with disease-free survival $(\mathrm{p}=0.039$ and 0.04$)$. On multivariate analysis, only the number of $\mathrm{CD}_{2} 5^{+}$lymphocytes showed an association with disease-free survival $(\mathrm{p}=0.036)$, whereas both factors showed an independent association with overall survival $(\mathrm{p}=$ 0.007 and 0.003). Contrarywise, the CD25 expression on SCCHN tumor cells was not associated with disease-free survival nor with overall survival. The presence of a high number of SCCHN-infiltrating $\mathrm{CD} 4{ }^{+} \mathrm{CD} 25^{+}$lymphocytes is associated with a good prognosis in SCCHN patients. Contrarywise, the CD25 expression on SCCHN tumor cells is not associated with a prognosis in SCCHN patients, and its role and meaning remains to be elucidated.
\end{abstract}

Key words: prognosis, squamous-cell carcinoma of the head and neck, CD25, lymphocytes

Address reprint requests to: Christophe Van de Wiele; Department of Nuclear Medicine, University Hospital Ghent,

De Pintelaan 185, 9000-B Ghent, Belgium; Tel.: +003292403028; Fax: 003292403807

E-mail: christophe.vandewiele@ugent.be

\section{INTRODUCTION}

Squamous-cell carcinoma of the head and neck (SCCHN), the sixth most frequent tumor in the world, is characterized by the infiltration of different subsets of tumor-infiltrating lymphocytes 
(TILs or $\mathrm{CD}^{+}$cells). ${ }^{1}$ TILs are present in a greater amount in the earlier stages of SCCHN disease, with the relative proportion of $\mathrm{CD}^{+}{ }^{+} \mathrm{CD}^{+}{ }^{+}$or $\mathrm{T}$-helper cells being higher than, or at least equal to, $\mathrm{CD} 3^{+} \mathrm{CD}^{+}$suppressor/cytotoxic T-cells. ${ }^{2}$ Of interest, a subset of $\mathrm{CD}^{+}{ }^{+} \mathrm{CD} 4{ }^{+}$cells in SCCHN express CD25 (the interleukin-2 receptor [IL-2R] alpha chain). $\mathrm{CD} 25$ is expressed on $\mathrm{CD}^{+}{ }^{+} \mathrm{CD} 4^{+}$cells following the activation by recognition of nonself antigens or tumor-associated antigens. SCCHN tumor-associated antigens include CEA, NY-ESO-1, MAGE-1, and MAGE-3. Activated $\mathrm{CD} 3{ }^{+} \mathrm{CD} 4{ }^{+} \mathrm{CD} 25^{+}$cells may inhibit tumor growth by lysing tumor cells or by secreting cytokines interferon-gamma ([IFN- $\gamma]$, tumor necrosis factor [TNF] $\alpha$, and so forth). ${ }^{3,4}$ Activated $\mathrm{CD} 3{ }^{+} \mathrm{CD} 4^{+} \mathrm{CD} 25^{+}$cells may also play a major cooperative role for $\mathrm{CD}^{+}{ }^{+} \mathrm{CD} 4^{+} \mathrm{CD} 8^{+}$cells in in vivo tumor eradication and the promotion of recruitment of other antitumor effector cells, for example, macrophages and eosinophils. ${ }^{5-7}$

In SCCHN cell lines, expression of $\mathrm{CD}_{25} 5^{+}$has been reported to be either absent, low, or high. ${ }^{8-11}$ In only one study, respectively, by Wiedeman et al., human tissue SCCHN samples were studied. ${ }^{10}$ In this study, a low to absent expression of CD25 was observed on SCCHN tumor cells; however, only four resection specimens were analyzed. Also, the relationship between CD25 expression on SCCHN and patient outcome is currently unknown.

This study reports on the expression of CD25 on lymphocytes and on SCCHN tumor cells assessed by means of immunohistochemistry, on instantly snap-frozen resection or biopsy specimens of primary human SCCHN, obained in a consecutive series of 35 patients. Histologic results obtained were related to overall, diseasefree survival.

\section{PATIENTS AND METHODS}

\section{Patients}

This study was approved by the Ethics committee of the University Hospital Ghent (Ghent, Belgium). Thirty-five (35) successive patients with a clinical or iconographic suggestive SCCHN were included in the study following written, informed consent over a period of 1 year, starting in June 2001. All patients underwent a systematic staging after a direct laryngoscopy and tissue biopsy diagnosis with planar chest radio- graphs, serum chemistry, and liver function analyses, and a contrast-enhanced computed tomography (CT) scan of the head and neck. The American Joint Committee on Cancer (AJCC) version 6 tumor node metastases (TNM) criteria were used for stage delineation. Baseline staging incorporated all physical findings, diagnostic imaging, and available pathology results. In all patients, treatment was performed with curative intent and consisted of definitive resection, with or without adjuvant radiotherapy, or primary radiotherapy, with or without combined lymph node dissection of the neck, and with or without chemotherapy. After the completion of treatment, patients underwent routine surveillance every $1-3$ months. In all patients, a tumor specimen or biopsy was obtained prior to treatment instigation, immediately snap frozen by using liquid nitrogen, and imbedded in a conservation medium and conserved by $-80^{\circ} \mathrm{C}$.

\section{Methods}

\section{Assessment of the level of inflammation}

To assess the degree of inflammation, hematoxylin and eosin (H\&E)-stained sections from neutral buffered formalin-fixed tissue were scored in a blinded fashion by using a five-point scale: 0 , no inflammation; 1 , very weak level of inflammation; 2, weak level of inflammation; 3, moderate level of inflammation; and 4, high level of inflammation.

\section{Evaluation of CD25 on tumor specimens}

Five-millimeter $(5 \mathrm{~mm})$ sections were freed of paraffin, and endogenous peroxidase activity was blocked with $\mathrm{H}_{2} \mathrm{O}_{2}$. A primary antibody-targeting human CD25 (1:200 dilution; neoMarkers) was incubated for 1 hour at room temperature, followed by a secondary antibody incubation (biotinylated goat antimouse, 1:40 dilution) for 30 minutes at room temperature. Then, avidin biotin amplification (ABC kit; Dakocytomation, Glostrup, Denmark) was added for 30 minutes. Incubation with an AEC (3-amino-9-ethylcarbazole) chromogen kit (Sigma, St. Louis, MO) at room temperature for 5-10 minutes produced a red reaction pigment. CD25-positive tumor cells and lymphocytes were counted separately at a magnification of $400 \times$ by using a test grid with a $0.22-\mathrm{mm}^{2}$ area. Intensities of staining were classified from 0 (absent staining) to 4 (high staining). A score of 1,2 , or 3 corresponds, respectively, with very low, low, and intermediate intensity of staining. For each malignancy, a 
value designated as HSCORE was obtained after the application of the following algorithm for both tumor cells and lymphocytes: HSCORE $=\Sigma(\mathrm{I}+$ 1)xn, where I and $n$ represent the number of cells that stained at each intensity, respectively.

Double staining for CD3 and CD25 was performed to demonstrate that T-lymphocytes were CD25 positive. Sections were first incubated with monoclonal antibodies to $\mathrm{CD} 25$, then the reaction was revealed by incubating the sections with a streptavidin-fluorescein conjugate (fluorescein isothiocyanate). After the first reaction, a second reaction with primary antibodies to $\mathrm{CD} 3$ was induced, and fluorescence was obtained with a streptavidin-Texas red fluorescent conjugate. Control sections were incubated with a mixture of irrelevant monoclonal reagents with a similar isotype. Images were acquired by means of the Noran (Naarden, The Netherlands) confocal microscope, and three-dimensional stacks were acquired at a resolution of $0.1 \mu \mathrm{m}$ in the $x, y$, and $z$ axes.

\section{Statistical analysis}

Statistical analysis was performed by using the commercially available software package SPSS (Chicago, IL), version 12.0. The KolmogorovSmirnov test was used to check the normality of data distribution. Quantitative variables were compared by using a paired Student's $t$ test and analysis of variance or the Mann-Whitney and Kruskall-wallis tests if their distribution was not normal. Qualitative variables were compared by using the chi-square test. Correlation analysis was performed by using the two-tailed Pearson test in the case of normally distributed data or the Spearman-rank test in the case of not normal distributed data. Disease-free survival times were calculated from the date of definitive radiotherapy completion or the date of definitive surgery. Persistent or recurrent disease at a presenting primary site was scored as local disease failure. Disease-free survival took into account all disease events, including local, regional, and distant failures. Patients with persistent disease at the end of treatment were considered to have experienced failure at time zero. Patients with no signs of relapse were censored at the time of last follow-up or death. Overall survival was defined as the time from initial diagnosis until death or until last follow-up (right censored data). Overall survival took all deaths into account. For univariate and regression analysis, we dichotomized values according to the median values of the study cohort or either defined the best separating cut-off value. We dichotomized the following clinical covariates: T-stage (T0-T2 vs. T3-T4), N stage (N0-N1 vs. N2-N3), AJCC overall stage (stages I-III vs. IV) and age $(<60$ years vs. $\geq 60$ years). Local recurrence-free, as well as overall, survival times were estimated by the Kaplan-Meier method and log rank testing (two-tailed) to examine the predictive value of dichotomized values and other clinical risk factors for local disease control. Multivariate analysis was performed by using Cox regression analysis, including, in sequential order of statistical significance, those variables that were found to be significant in univariate analysis, followed by the interactive terms.

\section{RESULTS}

\section{Patient Characteristics}

Mean age of the patient population under study was 60.5 years (range, 43-82), and patient characteristics are presented in Table 1. Regional lymph node involvement was diagnosed in 22 patients (63\%). There were 8 women and 27 men. Six (6) patients presented with stage II disease, 7 suffered from stage III disease, and 22 patients suffered from stage IV disease.

In 9 patients, treatment consisted of resection of the primary tumor with unilateral lymph node

\begin{tabular}{|lr||}
\hline Table 1. Patient Characteristics & \\
\hline Characteristics & No. of patients \\
\hline Gender & \\
Men & 27 \\
Women & 8 \\
Primary tumor site & \\
Oral cavity & 17 \\
Oropharynx & 7 \\
Hypopharynx & 3 \\
Paranasal sinus & 1 \\
Larynx & 7 \\
Tumor staging & \\
T1 & 2 \\
T2 & 15 \\
T3 & 4 \\
T4 & 14 \\
Lymph node involvement & \\
N0 & 13 \\
N1 & 11 \\
N2 & 9 \\
N3 & 2 \\
Distant metastases & 35 \\
\hline
\end{tabular}



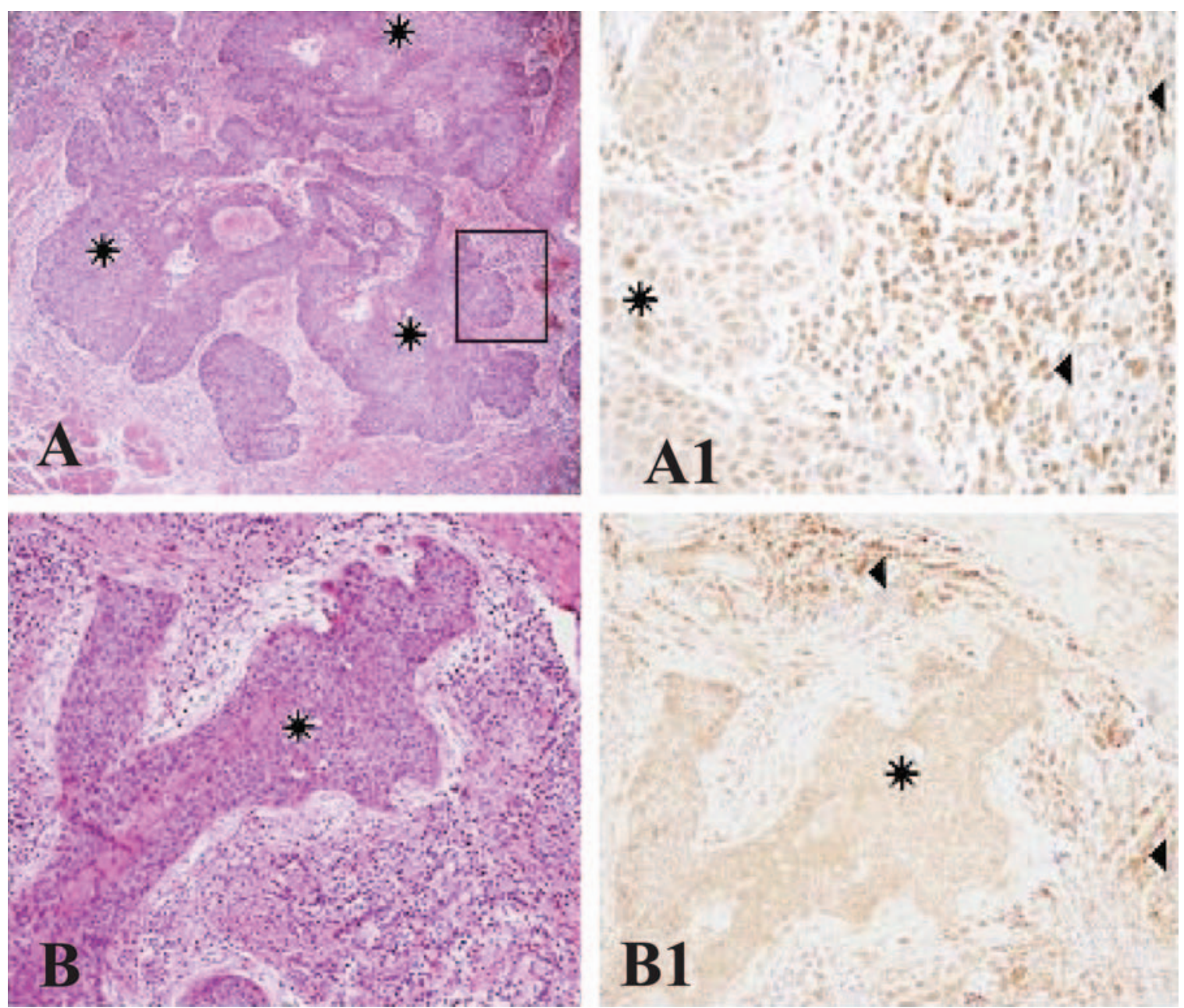

Figure 1. Squamous-Cell Carcinoma of the Head and Neck tumor with a high inflammatory infiltrate. Conventional immunostain: Panel A shows hematoxylin and eosin (H\&E) staining (magnification $200 \times$ ), asterisks indicate neoplastic cells. Panel A1 (area in the insert of panel A) shows CD25 staining; arrowheads indicate inflammatory cells (magnification 500 $\times$ ). Panel B shows H\&E stain (magnification 300×), asterisks indicate neoplastic cells. Panel B1 shows CD25 staining; arrowheads indicate inflammatory cells. Neoplastic cells (asterisk) show a diffuse immunostain for CD25. Confocal microscopy: Panel C shows a double immunostain for CD25, (panel $\mathbf{C 1}$ as single stain, fluorescein isothiocyanate (FITC) revealed, magnification $250 \times$ ) and CD3 (panel C2 as single stain, Texas red revealed, magnification $250 \times$ ). The fusion image (panel $\mathbf{C}$, magnification $500 \times$ ) demonstrates a diffuse CD25 and CD3 coexpression as a yellow color. Panel D shows a detail of two CD25-positive T-lymphocytes. Panel C1 shows a CD25 single stain, FITC revealed, magnification $1500 \times$ ); panel $\mathbf{C 2}$ shows a CD3 single stain, Texas red revealed, magnification $1500 \times$ ). The fusion image (panel $\mathbf{C}$, magnification $1500 \times$ ) demonstrate the CD25 and CD3 coexpression as a yellow color.

dissection $(n=5)$, with bilateral lymph node dissection $(n=1)$, or without lymph node dissection $(n=3)$. In 19 patients, treatment consisted of resection of the primary tumor with unilateral lymph node dissection $(n=15)$, with bilateral lymph node dissection $(n=1)$, or without lymph node dissection $(n=3)$, followed by adjuvant radiotherapy (cumulative dose, 60-70 Gy). Three (3) patients were treated by means of primary radiotherapy (cumulative dose, 70-75 Gy), in 2 of these patients after a unilateral and bilateral lymph node dissection. Finally, 4 patients were treated by means of radiochemotherapy (cumulative dose of $70 \mathrm{~Gy}$ combined with cisplatin at a dose of $100 \mathrm{mg} / \mathrm{m}^{2}$ on days 1,22 , and 43). Two (2) out of these 4 patients first underwent unilateral lymph node dissection and 1 patient bilateral lymph node dissection. Data on the presence of human papilloma or Epstein-Barr virus were not available. 


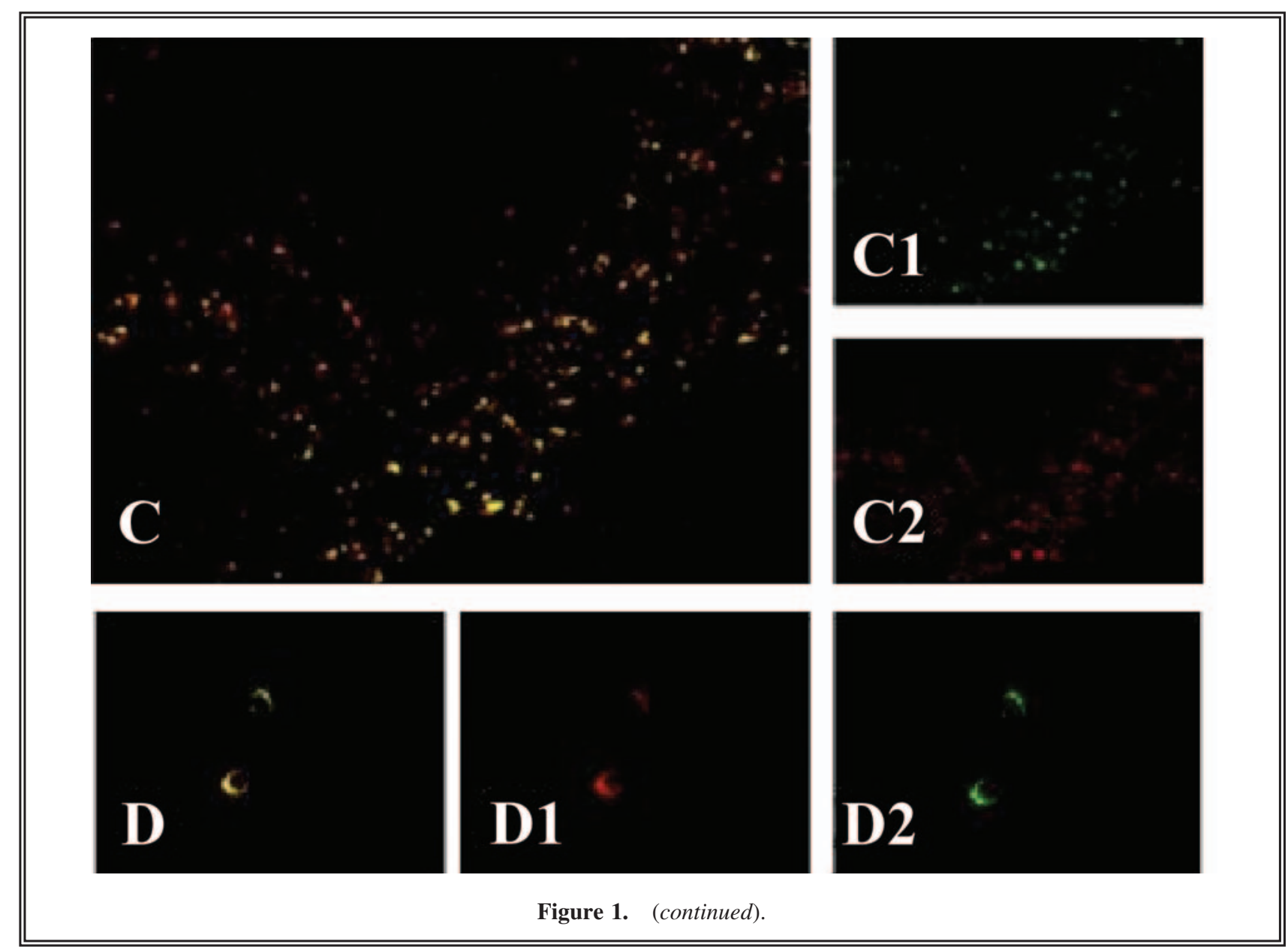

\section{Histologic Characterization}

CD25, on lymphoid cells

Twenty-five (25) of 35 tumor samples contained CD25 positive lymphocytes (mean number of positive cells/field of view for the total study population: 35; range, 0-120). In 18 samples, an intensity score of 3 or 4 was observed. Mean CD25 lymphocyte HScore was 108 (range, 0-480). The number of CD25-positive lymphoid cells or HScore did not differ significantly between different TNM stage or histologic grade. Contrarywise, a higher number of CD25-positive lymphocytes as well as HScore was found in samples with an increasing degree of inflammation (grades 3 and 4 vs. grade 2 inflammation, $p=0.001$; Fig. 1 ).

\section{CD25 on neoplastic cells}

CD-25 staining on neoplastic cells was positive in 18 of 35 biopsy specimens (mean number of positive cells/field of view for the total study pop- ulation: 16; range, 0-60). These patients formed the CD25-neoplastic-cell-positive group for dichotomization. With the exception of one tumor sample, density score was $\leq 2$. Mean CD25 tumor cells Hscore was 30 (range, 0-120). The number of CD25-positive neoplastic cells or HScore did not differ significantly between a different TNM stage or histologic grade. Contrarywise, there was a tendency toward lower numbers of CD25-positive neoplastic cells as well as HScore in samples with an increasing degree of inflammation (grades 3 and 4 vs. grade 2 inflammation, $p=0.08$; Fig. 1).

The number of CD25-positive lymphocytes was significantly higher than the number of CD25-positive neoplastic cells, respectively ( $p=$ 0.006). CD25 lymphocyte HScore was significantly higher than the CD25 tumor-cell HScore $(p=0.001)$.

Finally, the number of CD25-positive neoplastic cells and corresponding HScores did not correlate with the respective number of CD25-positive lymphocytes or Hscores. 


\begin{tabular}{||lcc|}
\hline \hline $\begin{array}{l}\text { Table 2. Univariate Analysis of the Relationship Between the Studied Variables and Disease- } \\
\text { Free and Overall Survival }\end{array}$ \\
\hline Variables & Disease-free survival, p (log-rank) & Overall survival, p (log-rank) \\
\hline Age & 0.28 (NS) & 0.67 (NS) \\
T-stage & $0.58(\mathrm{NS})$ & 0.45 (NS) \\
N-stage & $0.039^{*}$ & $0.007^{*}$ \\
Disease stage & $0.22(\mathrm{NS})$ & 0.21 (NS) \\
CD25 + Lymph nb & $0.04^{*}$ & $0.02^{*}$ \\
CD25 + Lymph Hscore & 0.23 (NS) & 0.24 (NS) \\
CD25 + Tum nb & 0.69 (NS) & 0.37 (NS) \\
CD25 + Tum Hscore & 0.77 (NS) & 0.45 (NS) \\
\hline
\end{tabular}

NS, not significant; *, statistically significant; Lym, lymphocyte; nb, number; Tum, tumor.

\section{Disease-Free Survival}

Median disease-free survival in the patients included in our study was 13.8 months (range, 2.2-42.1 months). On univariate analysis, only lymph node status dichotomized according to N0-N1 versus N2-N3 disease and the number of CD25-positive lymphocytes dichotomized by using a cut-off of $\geq 45$ cells field of view, were predictive of recurrence-free survival ( $p=0.039$ and 0.04) (see Table 2 and Fig. 2). The median diseasefree survival for patients with N0-N1 disease was 15.1 months, versus 12.6 months for patients with N2-N3 disease. The median disease-free survival for patients with low numbers of SCCHN CD25 ${ }^{+}$ infiltrating lymphocytes was 11.1 months $(n=20)$, versus 32.8 months for patients with high numbers of SCCHN CD25 ${ }^{+}$infiltrating lymphocytes $(n=$ 15 ). When both factors were included in the multivariate model, only the number of CD25-positive lymphocytes showed an association with diseasefree survival ( $p=0.036$ for the number of CD25 positive lymphocytes versus $p=0.249$ for lymph node status) (see Table 3).

\section{Overall survival}

At the time of data analysis, 15 patients had died and $93.3 \%$ of deaths seemed to be directly related to the original primary cancer (locoregional failure or metastatic disease). One (1) patient committed suicide. The median follow-up for the whole population was 17.6 months (range, 2.2-55.1 months). On univariate analysis, only $\mathrm{LN}$ status dichotomized according to N0-N1 versus N2-N3 disease and the level of SCCHN infiltrating CD25 ${ }^{+}$ lymphocytes were predictive of overall survival $(p=0.007$ and 0.02 ; see Fig. 3). Median overall survival for patients with N0-N1 disease was 27.9 months, versus 12.6 months for patients with N2-N3 disease. Median overall survival for patients with low numbers of SCCHN CD25 ${ }^{+}$infiltrating lymphocytes was 13.7 months, versus 39.4 months for patients with high numbers of SCCHN $\mathrm{CD} 25^{+}$infiltrating lymphocytes (see Table 2). When both factors were included in the multivariate model, both $\mathrm{N}$-status and the number of CD25 positive lymphocytes showed an independent association with overall survival $(p=0.007$ for the number of CD25-positive lymphocytes and $p=$ 0.003 for lymph node status) (see Table 3 ).

\section{DISCUSSION}

In this study, we show that high levels of tumorinfiltrating $\mathrm{CD} 25^{+}$T-lymphocytes are signifi-

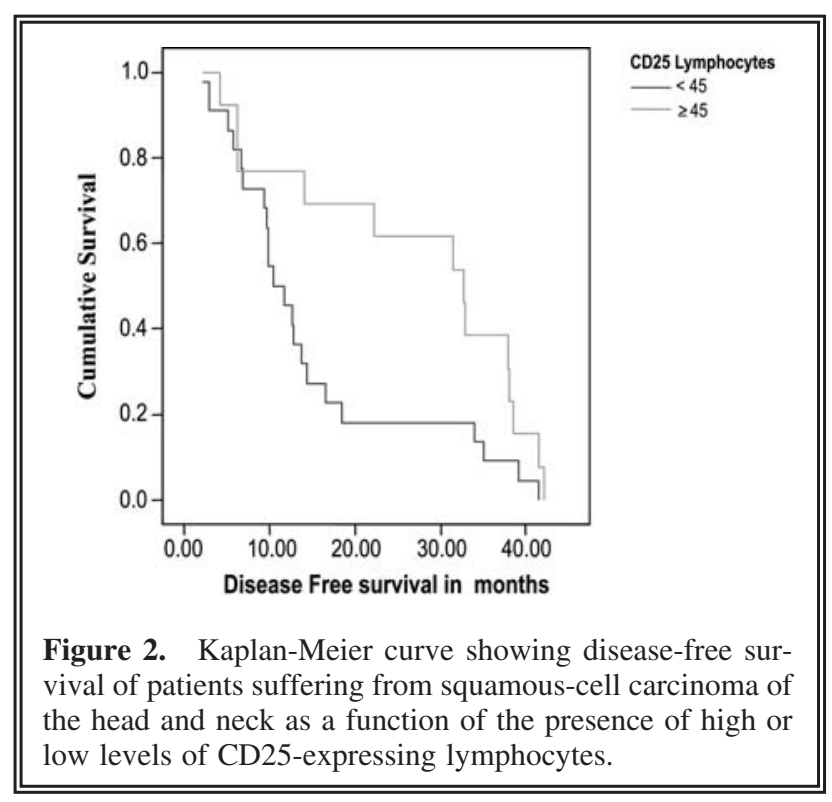




\begin{tabular}{|c|c|c|}
\hline Variables & Disease-free survival, p (log-rank) & Overall survival, p (log-rank) \\
\hline N-stage & 0.25 (NS) & $0.003^{*}$ \\
\hline CD25 + Lymph nb & $0.036^{*}$ & $0.007 *$ \\
\hline
\end{tabular}

cantly associated with better survival and especially with locoregional control in SCCHN patients. Available data on the potential prognostic value of T-cell infiltrations in SCCHN are limited. In a series of 16 patients by Snyderman et al., 2 of 8 patients with a $\mathrm{CD} 4^{+} / \mathrm{CD}^{+}$ratio of less than 1 developed cervical metastases, whereas 6 of 8 patients with a $\mathrm{CD} 4^{+} / \mathrm{CD}^{+}{ }^{+}$ratio greater than 1 developed cervical metastases. ${ }^{12}$ Based on their findings, the researchers suggested that a $\mathrm{CD} 4^{+} / \mathrm{CD} 8^{+}$ratio greater than 1 may be a useful prognostic indicator of the development of cervical metastases. More recently, Badoual et al. reported on the prognostic value of tumor-infiltrating $\mathrm{CD} 4{ }^{+} \mathrm{CD} 25^{+} \mathrm{T}$-cells and Tcell subpopulations in a series of 84 newly diagnosed, untreated patients with histologically proven primary head and neck cancer. ${ }^{13} \mathrm{Al}$ though not statistically significant, a trend toward longer survival $(p=0.059)$ and better locoregional control $(p=0.054)$ was observed in the group of patients with a high level of tumor-infiltrating $\mathrm{CD} 25^{+} \mathrm{T}$-cells at diagnosis. In the series presented, the number of tumor-infiltrating $\mathrm{CD} 4{ }^{+} \mathrm{CD} 25^{+} \mathrm{T}$-cells at the time of diagnosis proved of significant prognostic value for both disease-free and overall survival in multivariate analysis. In the series by Badoual et al., the median of tumor infiltration for $\mathrm{CD} 4{ }^{+} \mathrm{CD} 25^{+} \mathrm{T}$ cells was used to dichotomize patients in highand low-level groups of $\mathrm{CD} 4{ }^{+} \mathrm{CD} 25^{+} \mathrm{T}$-cells, whereas in our series, the best separating value (i.e., the value higher than the median value) was used. Given the trend observed in their series, it is highly likely that by optimizing their cut-off value, similar results to ours would have been obtained. In the series by Badoual et al., CD25 ${ }^{+}$ cells were further subdivided in two subsets for data analysis, respectively, in true helper effector T-cells $\left(\mathrm{CD} 4^{+} \mathrm{CD} 25^{+} \mathrm{CD} 69^{+}\right)$and in regulatory T-cells $\left(\mathrm{CD} 4^{+} \mathrm{CD} 25^{+} \mathrm{Foxp}^{+}\right.$or Treg cells). ${ }^{14-17}$ Treg cells have recently assumed a considerable importance within the immunoregulatory network in cancer as they exert suppres- sive activity upon $\mathrm{CD}^{+}$effector and $\mathrm{CD} 4^{+}$ helper T-cells and thus indirectly may promote tumor growth. The effects of Treg cells appear to be dose dependent, cell-contact dependent, cytokine dependent, and antigen nonspecific. Surprisingly, in multivariate analysis, the only significant prognostic factors related to locoregional control in the series by Badoual et al. were $\mathrm{CD} 4{ }^{+} \mathrm{CD} 25^{+} \mathrm{Foxp}^{+}$infiltration of the tumor and T-stage. The relationship between high levels of Foxp $3^{+} \mathrm{CD}^{+}$cells and locoregional control was hypothetically attributed to the suppressive effect of these cells on inflammation and the fact that inflammation may provide a favorable environment for tumor growth. ${ }^{18,19}$ In our series, the highest number of $\mathrm{CD} 4{ }^{+} \mathrm{CD} 25^{+} \mathrm{T}$-cells were found in those tumors eliciting the highest degree of inflammation. Our findings, together with the reported concordance of a $60 \%$ concordance between total $\mathrm{CD} 25^{+}$cell count and CD $25^{+}$Foxp $3^{+}$ cell count in the series by Badoual et al., suggests that the suppressive effect of Tregs on inflammation to explain its prognostic value for lo-

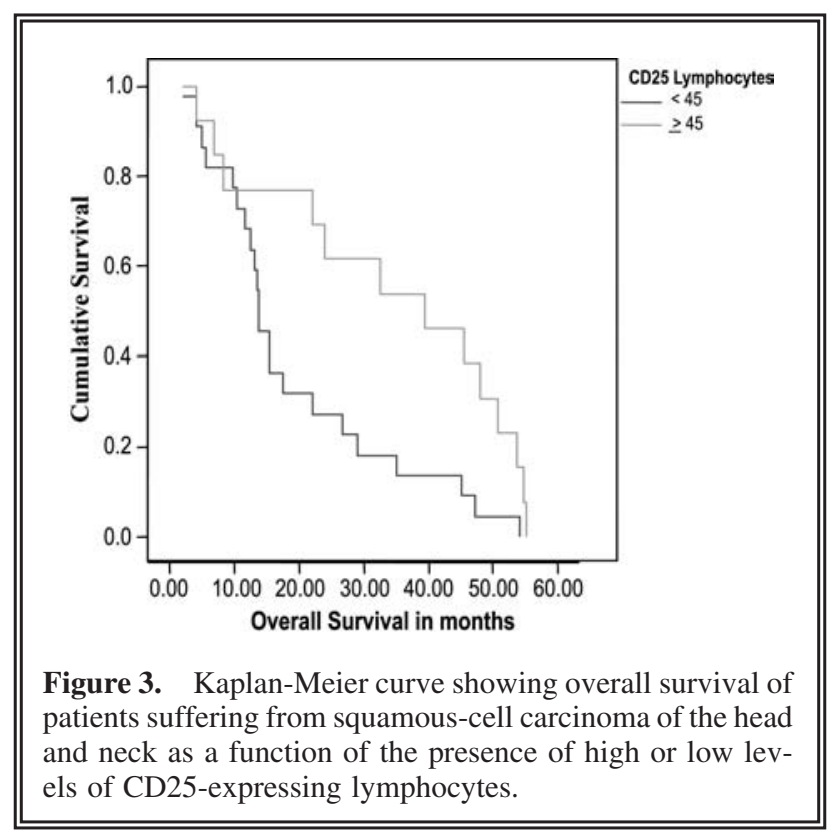


coregional control is only a small part of the global picture. More recent studies suggest that Tregs are a heterogeneous population within $\mathrm{CD}^{+}{ }^{+}$cells that can be further subdivided into different functional subsets, based on the expression of novel markers other than Foxp3, such as neurophilin-1 and glucocorticoid-induced tumor necrosis factor receptor (GITR). ${ }^{20,21}$ Given the emerging heterogeneity of Tregs, consideration should be given to the analysis of the interrelationship between these subsets of cells and how they influence and modulate the cancer process.

Previous studies on the presence of CD25 on SCCHN tumor cells mainly focused on cell lines. ${ }^{8-11}$ Reichert et al. and Yasumura et al. reported on the absence of CD25 on SCCHN cell lines, whereas Weidmann et al. found absent or only very weak staining of CD25 on SCCHN cell lines as well as in four fresh HNSCC tumor tissue samples. ${ }^{9-11}$ On the other hand, Cortesina et al. described the presence of high-affinity IL2-Rs on SCCHN with the expression of 200 binding sites for IL-2 with an affinity of $17 \times 10^{-12.8}$ Our series is the first that reports on the expression of $\mathrm{CD} 25^{+}$on SCCHN tumors in a larger series of patients, documenting SCCHN CD25 expression cells in 18 of 35 patients under study, albeit with mild to moderate intensity. Overexpression of CD25 on SCCHN tumor cells has been associated with tumor progression. ${ }^{22}$ Reported underlying molecular mechanisms responsible for the association between CD25 expression and tumor progression include Janus kinase 3 (Jak-3)-mediated increase in levels of cyclin-A, cyclin D, and cyclin-dependent kinases 2 and 4, resulting in an increase in cell proliferation, as well as the upregulation of antiapoptotic $\mathrm{BcX}-(\mathrm{L})$ and $\mathrm{Bcl}-2$ proteins, resulting in an increased resistance to chemotherapeutics. ${ }^{22}$ In the series presented, the number of CD25-positive tumor cells or related HScore proved not different between different histologic tumor grades, nor was there a relationship between either of these factors and disease-free or overall survival (regardless of the cut-off value used for dichotomization). Of interest, in the study by Cortesina et al., doses of 8-500 U/mL of IL-2 were able to inhibit the growth of 11 of 16 SCCHN lines tested. ${ }^{8}$ Also, in an immunosuppressed SCCHN xenografted nude mouse model, both locally and systemically administered rIL-2 significantly inhibited the growth of SCCHN. The absence of a significant inflammatory infiltrate in or around the xeno-grafts in this model, related to the immunosuppression, argued strongly for a direct effect of
IL-2 on tumor cells, rather than for an effector host macrophage-mediated effect. ${ }^{23}$ In this light, assessment of the relationship between the level of $\mathrm{CD} 25^{+}$expression on SCCHN cells to outcome to IL-2 therapy may be of interest.

\section{CONCLUSIONS}

In conclusion, the presence of a high number of SCCHN-infiltrating $\mathrm{CD} 25^{+}$lymphocytes is associated with a good prognosis in SCCHN patients. Contrarywise, CD25 ${ }^{+}$expression on SC$\mathrm{CHN}$ tumor was not related to patient outcome.

\section{REFERENCES}

1. Hoffmann TK, Whiteside TL, Bier H. Squamous-cell carcinoma of the head and neck. Principles and current concepts of immunotherapy. HNO 2005;53:285.

2. Boheim K, Denz H, Boheim C, Glassl H, Huber H. An immunohistologic study of the distribution and status of activation of head and neck tumor infiltrating leukocytes. Arch Otorhinolaryngol 1987;244:127.

3. Bourgeois C, Veiga-Fernandes H, Joret AM, Rocha B, Tanchot C. CD8 lethargy in the absence of CD4 help. Eur J Immunol 2002;32:2199.

4. Kurts C, Carbone FR, Barnden M, Blanas E, Allison J, Heath WR, Miller JF. CD4 ${ }^{+}$T-cell help impairs CD8 ${ }^{+}$ T-cell deletion induced by cross-presentation of selfantigens and favors autoimmunity. J Exp Med 1997; 186:2057.

5. Bevan MJ. Helping the CD8(+) T-cell response. Nat Rev Immunol 2004;4:595.

6. Dudley ME, Wunderlich JR, Robbins PF, Yang JC, Hwu P, Schwartzentruber DJ, Topalian SL, Sherry R, Restifo NP, Hubicki AM, Robinson MR, Raffeld M. Cancer regression and autoimmunity in patients after clonal repopulation with antitumor lymphocytes. Science 2002;298:850.

7. Greenberg PD. Adoptive T-cell therapy of tumors: Mechanisms operative in the recognition and elimination of tumor cells. Adv Immunol 1991;49:281.

8. Cortesina G, Sacchi M, Galeazzi E, Johnson JT, Whiteside TL. Interleukin-2 receptors on squamous-cell carcinomas of the head and neck. Characterization and functional role. Acta Otolaryngol 1992;112:370.

9. Reichert TE, Nagashima S, Kashii Y, Stanson J, Gao G, Dou QP, Whiteside TL. Interleukin-2 expression in human carcinoma cell lines and its role in cell cycle progression. Oncogene 2000;19:514.

10. Weidmann E, Sacchi M, Plaisance S, Heo DS, Yasumura S, Lin WC, Johnson JT, Herberman RB, Azzarone B, Whiteside TL. Receptors for interleukin-2 on human squamous-cell carcinoma cell lines and tumor in situ. Cancer Res 1992;52:5963. 
11. Yasumura S, Lin W, Weidmann E, Hebda P, Whiteside T. Expression of interleukin-2 receptors on human carcinoma cell lines and tumor growth inhibition by interleukin-2. Int J Cancer 1994;59:225.

12. Snyderman CH, Heo DS, Chen K, Whiteside TL, Johnson JT. T-cell markers in tumor-infiltrating lymphocytes of head and neck cancer. Head Neck 1989;11:331.

13. Badoual C, Hans S, Rodriguez J, Peyrard S, Klein C, Agueznay Nel H, Mosseri V, Laccourreye O, Bruneval P, Fridman WH, Brasnu DF, Tartour E. Prognostic value of tumor-infiltrating $\mathrm{CD} 4{ }^{+}{ }^{+}$-cell subpopulations in head and neck cancers. Clin Cancer Res 2006;12:465.

14. Fontenot JD, Gavin MA, Rudensky AY. Foxp3 programs the development and function of $\mathrm{CD} 4{ }^{+} \mathrm{CD} 25^{+}$ regulatory T-cells. Nat Immunol 2003;4:330.

15. Hori S, Nomura T, Sakaguchi S. Control of regulatory T-cell development by the transcription factor Foxp3. Science 2003;299:1057.

16. Sakaguchi S. Naturally arising $\mathrm{CD} 4{ }^{+}$regulatory T-cells for immunologic self-tolerance and negative control of immune responses. Annu Rev Immunol 2004;22:531.

17. Shevach EM. CD ${ }^{+} \mathrm{CD} 25^{+}$suppressor T-cells: More questions than answers. Nat Rev Immunol 2002;2:389.
18. Balkwill F, Coussens LM. Cancer: An inflammatory link. Nature 2004;431:405.

19. Erdman SE, Sohn JJ, Rao VP, Nambiar PR, Ge Z, Fox $\mathrm{JG}$, Schauer DB. CD $4{ }^{+} \mathrm{CD} 25^{+}$regulatory lymphocytes induce regression of intestinal tumors in ApcMin/+ mice. Cancer Res 2005;65:3998.

20. Shevach E, Stephens G. The GITR-GITRL interaction: Costimulation or contrasuppression of regulatory activity. Nat Rev Immunol 2006;6:613.

21. Yi H, Zhen Y, Jiang L, Zheng J, Zhao Y. The phenotypic characterization of naturally regulatory CD $4{ }^{+} \mathrm{CD} 25^{+}$T-cells. Cell Mol Immunol 2006;3:189.

22. Kuhn DJ, Smith DM, Pross S, Whiteside TL, Dou QP. Overexpression of interleukin-2 receptor alpha in a human squamous-cell carcinoma of the head and neck cell line is associated with increased proliferation, drug resistance, and transforming ability. J Cell Biochem 2003;89:824.

23. Sacchi M, Snyderman CH, Heo DS, Johnson JT, d'Amico F, Herberman RB, Whiteside TL. Local adoptive immunotherapy of human head and neck cancer xenografts in nude mice with lymphokine-activated killer cells and interleukin-2. Cancer Res 1990;50:3113. 